\title{
THE USE OF THE PULHEEMS SYSTEM OF MEDICAL CLASSIFICATION IN CIVILIAN PRACTICE
}

\author{
BY \\ M. D. WARREN \\ From the London County Council
}

(RECEIVED FOR PUBLICATION FEBRUARY 6, 1956)

In 1948 the three Armed Services adopted the Pulheems system of medical classification. Since then it has been suggested that such a system would be of benefit in industry (Fletcher, 1949; Lewis, 1952). This paper studies the results obtained from applying the Pulheems system to 1,000 applicants for civilian employment.

\section{The Pulheems System}

The Pulheems system, described in detail by Fletcher (1949) and in various official Service publications, consists of an assessment of seven different "qualities" designated as follows :-

$\mathbf{P}=$ Physical capacity including physique, general medical condition, and any systematic disease

$\mathbf{U}=$ Upper limbs, considered functionally

$\mathbf{L}=$ Locomotion, also considered functionally

$\mathbf{H}=$ Hearing measured as follows :-

H1 is ability to hear a forced whisper at 20 feet in each ear separately; $\mathrm{H} 2$ can hear forced whisper at 10 feet in each ear separately; $\mathrm{H} 3$ can hear forced whisper with both ears together at $10 \mathrm{feet}$; and $\mathrm{H} 7$ can hear the conversational voice at 10 feet with both ears.

EE is visual acuity of the right and left eye respectively. E1 is equivalent to Snellen $6 / 6$, E2 to $6 / 9$, E3 to $6 / 12$, E4 to $6 / 18$, E5 to $6 / 24$, E6 to $6 / 36$, E7 to $6 / 60$, and E8 is less than $6 / 60$.

$M$ is mental capacity (intelligence), which is not usually measured by the medical officer.

$S$ is emotional stability, assessed particularly by reference to past history.

Each quality is given a number. For $\mathbf{P}$ and $\mathrm{EE}$ this may be any number from 1 to 8 , but $U, L$, and $H$ can only be $1,2,3,7$, or 8 , whilst $M$ and $S$ can only be $2,3,7$, or 8 . The number (or degree) represents the functional capacity of the quality. Degrees 1 and 4 imply functional efficiency above the average. The average is represented by degrees 2 and 5 , and 3 and 6 imply below-average functional efficiency. Degrees 1 to 3 allow employment any- where in the world, but 4 to 6 limit employment to temperate climates only. Degree 7 for any quality designates fitness for home service only and 8 means unfitness for any form of military service. These degrees are assessed on a functional basis and, to quote the document which introduced the Pulheems system to the Services, " the anatomical lesion should not in any way form the basis of classification". The more precise instructions do not entirely follow this ideal; thus they state: "Evidence of mitral or aortic incompetence is a reason for placing in P8." and "Active pulmonary tuberculosis or evidence that the disease has been active within the past five years places a man in P8"... "Mild, non-incapacitating asthma will limit to P6".

As far as possible in this survey, the strict military interpretation has been used. There would be no value in the widespread adoption of the Pulheems system for civilian use if each undertaking had its own interpretations and gradings.

\section{The Present Investigation}

Starting on January 1, 1955, after a previous short trial to ascertain the best method of recording the findings, each applicant presenting for preemployment medical examination was given a Pulheems category (or profile). The first 600 men and 400 women seen were taken. No other selection was made.

The age, sex, and occupational grouping of these 1,000 people are shown in Table 1. Altogether there were 73 occupations (excluding different ranks within an occupation). The types of employment that have been grouped together are "teachers", including teachers, teacher-trainees, and physical training instructors; "firemen and ambulance drivers", who include ambulance attendants; "clerical and social workers" includes administrative and clerical staff, nurses, health visitors, mid- 
wives, doctors, solicitors, architects, engineers, and other professional workers; " other" includes park keepers, gardeners, building trade operatives, messengers, porters, warehousemen, laundry women, drivers, cooks and domestics, cleaners, schoolkeepers, school inquiry officers, and unskilled labourers.

TABLE 1

AGE, SEX, AND OCCUPATIONAL DISTRIBUTION OF APPLICANTS FOR EMPLOYMENT

\begin{tabular}{|c|c|c|c|c|c|c|}
\hline$\underset{\text { Group }}{\text { Age }}$ & Teachers & $\begin{array}{c}\text { Firemen } \\
\text { and } \\
\text { Ambulance } \\
\text { Drivers }\end{array}$ & $\begin{array}{c}\text { Clerical } \\
\text { and } \\
\text { Social } \\
\text { Workers }\end{array}$ & Other & Total & \\
\hline $\begin{array}{c}\text { Men } \\
11-15 \\
16-20 \\
21-25 \\
26-30 \\
31-35 \\
36-40 \\
41-45 \\
46-50 \\
51-55 \\
56-60 \\
61-65 \\
66-70\end{array}$ & $\begin{array}{r}3 \\
52 \\
64 \\
36 \\
24 \\
12 \\
10 \\
3 \\
3 \\
1 \\
2\end{array}$ & $\begin{array}{r}7 \\
20 \\
20 \\
10 \\
7 \\
3 \\
6 \\
2 \\
1 \\
-\end{array}$ & $\begin{array}{r}\overline{10} \\
15 \\
40 \\
42 \\
16 \\
11 \\
5 \\
11 \\
5 \\
-\end{array}$ & $\begin{array}{r}3 \\
5 \\
19 \\
25 \\
26 \\
16 \\
22 \\
23 \\
11 \\
8 \\
3 \\
1\end{array}$ & $\begin{array}{r}3 \\
22 \\
106 \\
149 \\
114 \\
63 \\
48 \\
44 \\
27 \\
17 \\
4 \\
3\end{array}$ & \\
\hline Total & 210 & 73 & 155 & 162 & 600 & \\
\hline Women & & & & & & $\begin{array}{l}\text { Total } \\
\text { men and } \\
\text { women }\end{array}$ \\
\hline $\begin{array}{l}11-15 \\
16-20 \\
21-25 \\
26-30 \\
31-35 \\
36-40 \\
41-45 \\
46-50 \\
51-55 \\
56-60 \\
61-65 \\
66-70\end{array}$ & $\begin{array}{r}19 \\
86 \\
42 \\
22 \\
17 \\
8 \\
10 \\
7 \\
1 \\
3 \\
-\end{array}$ & $\begin{array}{l}\frac{-}{1} \\
\frac{1}{1} \\
\frac{1}{z} \\
= \\
=\end{array}$ & $\begin{array}{r}\overline{16} \\
33 \\
28 \\
36 \\
14 \\
17 \\
13 \\
3 \\
3 \\
-\end{array}$ & $\begin{array}{l}-1 \\
5 \\
2 \\
5 \\
3 \\
6 \\
2 \\
4 \\
- \\
-\end{array}$ & $\begin{array}{r}7 \\
26 \\
125 \\
73 \\
63 \\
35 \\
32 \\
25 \\
14 \\
4 \\
3 \\
-\end{array}$ & $\begin{array}{r}3 \\
48 \\
231 \\
222 \\
177 \\
98 \\
80 \\
69 \\
41 \\
21 \\
7 \\
3\end{array}$ \\
\hline Total & 205 & 4 & 163 & 28 & 400 & \\
\hline $\begin{array}{l}\text { Total } \\
\text { men and } \\
\text { women }\end{array}$ & 415 & 77 & 318 & 190 & 1,000 & 1,000 \\
\hline
\end{tabular}

The sex distribution was nearly equal in the two groups headed " teachers" and " clerical and social workers" (which among the males included mainly professional and administrative staff and among the females nurses, social workers, and clerical staff). There was a marked excess of men in the "firemen and ambulance drivers" group, the four women all being ambulance drivers. There was also an excess of men in the "other" group.

The age distribution shows that the women were slightly younger than the men, and this was very marked among the teachers, where half the women were under 25 years but only a quarter of the men were so aged. Taking both sexes together about a quarter of the people examined were over 40 years of age.

Applying the Pulheems classification it was found that 278 men $(46.3 \%)$ and $177(44 \cdot 2 \%)$ women, a
TABle 2

INCIDENCE OF BELOW-AVERAGE QUALITIES

\begin{tabular}{|c|c|c|c|c|c|c|c|}
\hline Quality & Degree & Men & Women & Quality & Degree & Men & Women \\
\hline $\mathbf{P}$ & $\begin{array}{l}3 \\
6 \\
7 \\
8\end{array}$ & $\begin{array}{r}8 \\
11 \\
24 \\
66\end{array}$ & $\begin{array}{r}9 \\
8 \\
16 \\
28\end{array}$ & H & $\begin{array}{l}2 \\
3 \\
7 \\
8\end{array}$ & $\begin{array}{l}4 \\
9 \\
1 \\
1\end{array}$ & $\begin{array}{l}\overline{3} \\
-\end{array}$ \\
\hline \multirow[t]{2}{*}{$\mathbf{U}$} & \multirow[t]{2}{*}{3} & \multirow{2}{*}{$\frac{3}{-}$} & \multirow{2}{*}{$\frac{3}{-}$} & $\mathbf{M}$ & 3 & 1 & - \\
\hline & & & & $\mathbf{S}$ & \multirow{2}{*}{$\begin{array}{l}3 \\
7 \\
8\end{array}$} & \multirow{2}{*}{$\begin{array}{l}11 \\
2 \\
9\end{array}$} & \multirow{2}{*}{$\begin{array}{r}10 \\
3 \\
7\end{array}$} \\
\hline $\mathbf{L}$ & $\begin{array}{l}3 \\
7 \\
8\end{array}$ & $\begin{array}{r}27 \\
8 \\
5\end{array}$ & $\begin{array}{r}34 \\
1 \\
3\end{array}$ & & & & \\
\hline
\end{tabular}

total of $455(45.5 \%)$ people, had a normal or average profile of Pulheems (22211122). Table 2 shows the numbers with lower degrees in all the categories except EE (visual acuity). Excluding defective hearing and defective vision $156(26 \%)$ of the men and $100(25 \%)$ of the women showed one defect or more. (These figures are less than the totals of the figures in Table 2 as some persons showed multiple defects.) One hundred and nine $(18 \%)$ of the men and $61(15 \%)$ of the women were classified below P2, the majority being P7 or P8. $P$ reflects more than physique alone; it is the " master quality" and can be affected by the other qualities. Thus a man with normal hearing but with chronic discharging otitis media would be classified $\mathrm{P} 8 \mathrm{H} 1$, and from a civilian point of view he would be fit for most types of employment.

After $P$ the next most frequently defective quality was $L$. This showed an interesting sex difference, with $40(6.5 \%)$ ranked as defective in men and $38(9.5 \%)$ in women. The majority of these were L3 on account of minor foot defects, flat feet and varicose veins in men and hallux valgus in women. Quality $\mathbf{H}$ also showed an interesting sex difference, with $2.5 \%$ of the men but only $0.75 \%$ of the women having a defect graded as $\mathrm{H} 3$ or lower, measured as indicated above. Only two men were really hard of hearing. No tests were carried out for M (intelligence) but one known mental defective was examined. The assessment of quality $\mathbf{S}$ (emotional stability) depends mainly on the history, S3 signifying a definite history of a nervous breakdown or other mental trouble from which the person has recovered whilst $\mathbf{S} 7$ or 8 shows that the person is either very liable to recurrence or shows signs of existing instability. Twenty-two $(3.7 \%)$ of the men and $20(5 \%)$ of the women gave a history of psychological disorder and in both sexes about half the applicants had symptoms or signs of instability at the time of examination, the most usual symptoms being insomnia, fatigue, and anorexia.

The purpose of the Pulheems system is to classify both persons and jobs so that by matching the profiles of the two it is possible for any person (not 
necessarily a doctor) to see the range of jobs for which the applicant is fit. Therefore, in the case of the $45 \%$ of applicants who had a normal Pulheems profile no useful purpose would have been served by adding their Pulheems profile to a straightforward statement that they were fit for employment. Thus, if the Pulheems system is to be of value it must be amongst the handicapped and the disabled that its advantages should lie. It is in this group that the foreman, supervisor, or headmaster needs precise guidance as to an employee's capabilities.

The fact that unfitness for military service, e.g., P8 or S8, is insufficient guide for civilian employment is revealed by this survey. Although $12.5 \%$ of men applicants and $9 \%$ of the women applicants had P8 or S8 categories which would render them unfit for military service, only $4.8 \%$ of the men and $0.75 \%$ of the women were considered unfit for the civilian posts for which they were examined. Consideration of the main causes for classifying people as P8 in this survey shows the need for many subdivisions of P8 if the Pulheems system is to be of use in civilian practice. Pulmonary tuberculosis, peptic ulcer, and chronic suppurative otitis media were the three most numerous causes of a P8 rating in men. In civilian life pulmonary tuberculosis is only a bar to employment if the clinical condition of the patient is such that the disease would be aggravated by his work and if the patient might be a source of infection to the public or to other employees. The disease need not be entirely quiescent, for some chest physicians now allow their patients to resume work while still under drug therapy. If these patients are to be categorized many different factors must be considered, not least the details of the proposed employment and its location. Furthermore, an employer would be more likely to allow an established employee to resume work, perhaps under sheltered conditions, than to take on a new employee in the same clinical state. A single category of P8 does not allow for these important factors. For tuberculosis alone it would be necessary to have separate categories which showed the amount of physical work the person could undertake, the possibility of infection, and whether an indoor or outdoor environment was advised. In addition each type of employment would have to be correspondingly graded.

Most patients with peptic ulcers are employable and a grading of $P 8$ is, from a civilian point of view, too low. The same applies to chronic suppurative otitis media, a disease that makes the sufferer unfit for military service. This condition is of little importance in civilian employment unless it is associated with deafness or occurs in food handlers or in people who need a particularly high standard of physical fitness, such as firemen.

Civilian employers under the Disabled Persons Act (1944) must employ at least $3 \%$ of registered disabled persons. Most concerns probably employ more than this quota. Judging by the figures in this survey at least $10 \%$ of the men and $6 \%$ of the women examined could have registered as disabled persons. Further, it by no means follows that the most disabled person is rejected, as for certain posts relatively minor defects are a bar to employment, such, for example, as defective eyesight in a fireman or ambulance driver.

\section{Anomalies and Modifications of the Pulheems System}

A system which attempts to overcome these defects of the Pulheems system has been elaborated by Hanman (1951) and according to Forssman (1955) a modification of Hanman's system has been tried out in Sweden with good results. The complexity of Hanman's system is indicated by the fact that he lists about 80 factors to be assessed, all of which may have a number of degrees. His system does not include any psychological factors.

In view of its apparent drawbacks it is interesting to consider the history of the development of the Pulheems system in the Army (Crew, 1953). At the start of the war four grades only were in use:-

$$
\begin{aligned}
& \text { Grade } A= \text { fit for general service, home and } \\
& \text { abroad } \\
& \text { Grade } B= \text { fit for garrison and base service, } \\
& \text { home and abroad } \\
& \text { Grade } C=\text { fit for home service only } \\
& \text { Grade } D=\text { unfit for military service }
\end{aligned}
$$

These grades took little account of the multiplicity of employments available in the Army and thus tended to exclude people with defects who would nevertheless be fit for the more sheltered jobs in the Army. The civilian medical boards classified all the men they examined in Grade I, II, III, or IV. Grade I was normal, Grade II indicated minor defects, Grade III marked disabilities or evidence of past disease, and Grade IV unfit for any form of military service. As the disabilities were not specified the Army found considerable difficulty in allocating personnel appropriately.

In 1940 a system of medical grading in terms of military employment was introduced. The categories were designated A1, A2, B1, B2, B3, B4, B5, $C, D$, and $E$. A1 meant that the individual could see to shoot or drive, could endure severe strain, had no defects of locomotion, and only minor, remediable disabilities. He was fit to serve anywhere in the world. A2 was similar to A1 except that slight defects of locomotion were present. Men in the 
B grades could only be employed on lines of communication, base or garrison duties, but could serve in the tropics, while men in the $\mathrm{C}$ grades were fit for home service only, had marked physical disabilities or evidence of past disease, and were considered unfit for considerable exertion. Grade D men were temporarily unfit and those in Grade E permanently unfit. Crew (1953) remarks :

\begin{abstract}
" Very soon after adoption it became apparent that large numbers of men were being placed in categories lower than those appropriate to their physical condition. The root of the matter was found to lie in the failure of medical officers when assessing physical capacity to distinguish clearly between the mere existence of a physical defect and the presence or absence of any functional disability arising directly as the result of that defect."
\end{abstract}

This is indeed the basic difficulty in all systems of medical classification, however complex they may be, for the amount of disability a defect causes depends as much on the personality and psychological environment as on the defect. Flat feet may not interfere with dancing, although they may be incapacitating when marching. A disability may be negligible as long as a job is congenial, but it may become unbearable when work palls. No satisfactory method of assessing these imponderable but essential qualities has been found. However, the Army continued to amend its system and having started with but four medical gradings had by 1943 introduced no fewer than 72 categories and subdivisions. The Pulheems system, originally adopted by the Canadian Army, was adopted by the British armed services in 1948. However, the difficulty of grading the individual soldier still remained. Crew (1953) writes:

“ In determining a man's category a medical officer specialist or medical board had to decide not as to a man's physical fitness to perform the job in which he was then engaged, but rather as to his capacity to perform all the numerous jobs which a man of his category might from time to time be called upon to undertake."

This led to wastage of manpower and was not overcome by the introduction of the Pulheems system. Indeed Crew reports:

" During preliminary trials it was found that $13 \%$ of personnel that would have been classified $\mathrm{A} 1$ and therefore fit for service in front line units under the old category system were relegated to less active duties largely on account of a low degree of assessment in respect of $M$ and $S$. Its greatest value was among personnel in the lower categories as it provided a finer screen."

Crew's finding is at variance with the experience of this survey, but the difference is due to the fact that the Services are not interested in finely screening major defects, all of which make an individual unfit for service, whereas these major defects are the very defects which need the finest screening in civilian practice. Lewis (1952) also mentioned some difficulties in the application of the Pulheems system.

“ The Pulheems system is not ideal. It depends a great deal upon subjective tests, which is a serious difficulty; also the provision of standards for comparisons presents a problem."

The R.A.F. also introduced the Pulheems system, but found that it did not provide a sufficiently fine screen for air-crew. Additional "employment standards" were therefore introduced which summarized the Pulheems profile and provided information to show the employability of an airman in respect of flying (Air or A) and ground duties (Ground or G). Under this system a fit pilot is graded A1G1 and normal ground staff are A4G1, meaning " fit to fly as a passenger and fit for all ground duties anywhere in the world".

In addition to the difficulties and anomalies in the use of the Pulheems system experienced by the Services, other and wider problems are raised by its application in civilian life. First, in civilian practice there is a far greater range of ages, skills, and occupations than in the Services. Secondly, as has already been discussed, men in category P8 (unfit for military service) may be employable outside the Services. It is unthinkable that an individual who was found unfit for military service should ipso facto be denied employment in civilian life. Thus the lowest categories would need considerable breakdown and elaboration. Thirdly, the majority of employees apply for a specific occupation. For instance, a teacher applies to be a teacher and is not interested to know that he could also be a fireman, clerk, or sewer flusher; nor is the employer interested in this additional information.

Other objections to the widespread use of Pulheems may be made on ethical grounds. It is necessary to keep in mind the purposes and limitations of pre-employment medical examinations. The objects of the examination have been stated by Stevenson (1950) as (1) to protect a prospective employee from work which would endanger his health, and (2) to advise the employer as to the limitations of an applicant for employment. Newquist (1955), discussing this problem, also mentions: (3) to discover any correctable or controllable defects; (4) to provide a health base line for future comparative study; (5) to detect any communicable disease. And to these may be added (6) to protect the public and other employees from danger arising as a result of a disability in a fellow employee. 
With the exception of (2) above, none of these purposes would be helped by the introduction of a system of categories. A clear statement by an industrial medical officer who is familiar with the requirements of the occupation regarding a man's fitness for that occupation is of greater value than a numerical summary of the applicant's physical and mental qualities. Every prospective employee should be considered individually for his work and no decision should be prejudiced because a military grading has previously been applied to him.

During the course of this investigation an unexpected value of the Pulheems system (or a modification of it) came to light. It was found useful as a ready-made numerical coding for statistical purposes. Figures covering each system of the body can be rapidly produced and compared. This part of the paper considers the incidence of the defects discovered during the investigation, relates this to other published data, and discusses the value of pre-employment medical examinations in the study of the general incidence of defects and disease in the population.

\section{Results}

The incidence of the main defects discovered in the population shown in Table 1 is shown in Table 3. But before discussing the incidence of these defects it is necessary to consider the limitations of the figures presented.

These figures cannot by themselves be taken as precise measures of the figures in the general population, for there are many biases. The prospective employee first selects himself for the job; in this survey only $12 \%$ of the firemen and ambulance drivers had defective vision, whereas the incidence in the whole group was $37 \%$. Some people who fear they may be rejected on medical grounds no doubt avoid applying for a post with a concern known to carry out medical examinations of its employees. Some people are less than frank in their medical histories when applying for a job while they might exaggerate their disabilities to a National Service Medical Board. Other people might be too disabled to seek work; the low incidence of mental defects in this group of applicants may be due to this. Judging from the figures presented here there may also be a tendency for disabled women to stay at home, in contrast to the man who must seek some work. All these factors and others, such as the varying standards of medical examination between different investigators make the results of this investigation inapplicable to the population as a whole. Nevertheless, within these limitations some interesting points emerge.
TABLE 3

INCIDENCE OF DEFECTS

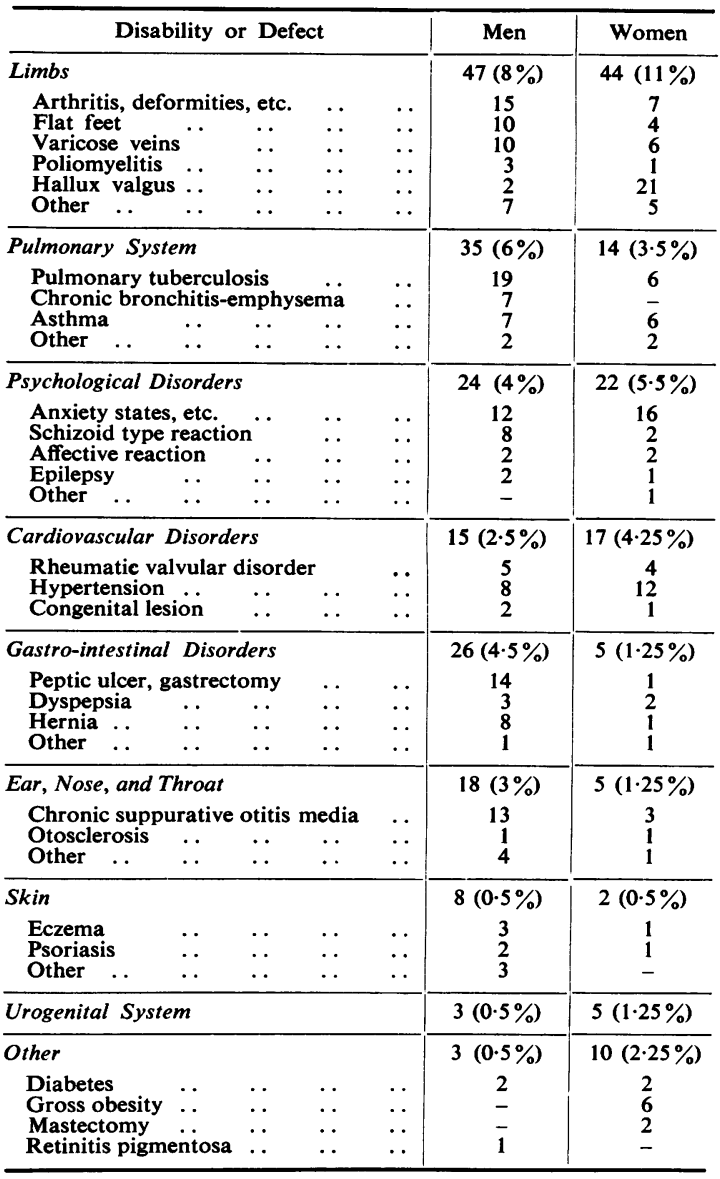

Foot Defects.-Defects of locomotion, particularly hallux valgus, showed a striking sex difference. Twenty-one $(5.25 \%)$ of the women applicants had hallux valgus compared with only two $(0.3 \%)$ of the men applicants. Flat foot was found in $10(1.7 \%)$ of the men applicants and in four $(1 \%)$ of the women; varicose veins were noted also in $10(1.7 \%)$ of the men and in six $(1.5 \%)$ of the women. Hewitt, Stewart, and Webb (1953) found the incidence of hallux valgus among male recruits examined for National Service to be $2 \cdot 8 \%$. These authors also found that there was an increased incidence in the lower social classes and that the incidence increased from $1.39 \%$ in men aged $17-19$ years to $4.69 \%$ in those aged 40-44 years. When the rather small figures of the present survey were broken down into age groups it was found (Table 4) that the incidence in the women increased considerably with age; whether 
this finding is due only to age or to some past fashion in ladies' footwear is not known. When their previous occupations were considered it was found that no less than one-third of the female applicants with hallux valgus had always been in sedentary work. No apparent social class difference was found.

TABLE 4

INCIDENCE OF HALLUX VALGUS BY AGE (FEMALE APPLICANTS)

\begin{tabular}{c|c|c}
\hline Age (yr.) & No. of Applicants & No. with Hallux Valgus \\
\cline { 1 - 2 } Under 21 & 26 & -5 \\
$21-30$ & 198 & 5 \\
$31-40$ & 98 & 4 \\
$41-50$ & 57 & 6 \\
$51-60$ & 18 & 1 \\
$61-70$ & 3 & 21 \\
\hline Total .. & 400 & \\
\hline
\end{tabular}

Pulmonary Tuberculosis. - A history of pulmonary tuberculosis was given by $19(3.1 \%)$ of the men applicants and by six $(1.5 \%)$ of the women. These figures show the usual male preponderance and are within the limits of the figures found in mass radiological and other surveys. It is usually considered that $2-5 \%$ of adults have latent active lesions or recent (within five years) histories thereof. The rejection rate found among National Service recruits varied between $0.8 \%$ and $3.6 \%$ (Lee, 1955; Stewart, Webb, and Hewitt, 1955).

Psychoses, Neuroses, and Epilepsy.-A history of disabling neurosis was obtained from $12(2 \%)$ of the males and from $16(4 \%)$ of the females, showing the usual sex difference. The figures are almost certainly lower than the incidence in the population as a whole. Some cases were probably missed as there are no physical signs to mark a person recovered from a neurosis and the diagnosis is largely dependent on the history. The incidence of psychoses was $10(1.7 \%)$ in the males and four $(1 \%)$ in the females, again a low figure. The three cases of epilepsy found among these 1,000 applicants compares with the figure of 3 to 5 per 1,000 usually given as the incidence among the general population.

Cardiovascular Disease and Hypertension.-Hypertension (taken as a diastolic reading of over $100 \mathrm{~mm}$. $\mathrm{Hg}$ after resting if necessary) occurred in eight $(1.3 \%)$ of the males and $12(3 \%)$ of the females. It is difficult to differentiate between hypertensive disease and high blood pressure. Both Fishberg (1954) and Pickering (1955) have found that up to the age of puberty the blood pressure in the two sexes is approximately equal and then from adolescence to about the age of 40 the blood pressure of men is higher than that of women. This difference gradually becomes less marked and is reversed after the age of 40 . Neither of the above authors believes that the menopause itself plays any part in the pathogenesis of hypertensive disease which as a cause of death is slightly more common in men than in women. The females with hypertension in the present survey (of whom 11 were over the age of $\mathbf{4 0}$ years) might well include some within the upper range of normality.

The National Service rejection rate for hypertension (Stewart and others, 1955) was $0.5 \%$ but a marked age gradient was noted and the higher incidence in the older population considered here was to be expected.

Peptic Ulcers. - There was a large excess of males who gave a history of peptic ulcer, the figures being $14(2.3 \%)$ in the males and one $(0.25 \%)$ in the females. In service recruits Stewart and others (1955) found $1 \cdot 18 \%$ of men aged 17 to 44 years had peptic ulcers. There was a marked age gradient and the figures found in the present survey agree generally with Stewart's findings. Doll and Avery Jones (1951) calculated the incidence of peptic ulceration in London to be $5.8 \%$ in men and 1.9 in women.

Other Conditions.-There was a marked male excess of chronic suppurative otitis media and chronic bronchitis and emphysema were only found in men.

Visual Acuity.-Visual acuity was measured using Snellen's test type. Any person failing to read 6/6 in each eye separately was considered to be defective. Three hundred and seventy-six $(37.6 \%)$ of all the applicants were found to have a defect of vision, a finding very similar to that of Sorsby, Benjamin, and Yudkin (1955) who found some visual defect in $37 \%$ of adults between the ages of 21 and 40 . In this survey the incidence in men was $216(36 \%)$ of all men and $207(39 \%)$ if firemen and ambulance drivers are excluded. This difference illustrates the difficulties of making general deductions from figures obtained from pre-employment examinations, for both firemen and ambulance drivers are interviewed before their medical examination and only exceptionally would a person wearing spectacles be referred for examination. The incidence of defects in the women applicants was $160(40 \%)$, virtually the same as the $39 \%$ found in the men, excluding the firemen and ambulance drivers. Breaking the figures down into occupational groups there is little difference to be found, except that the less skilled groups ("other") showed a lower incidence of 
defect $(32 \%)$ than the remaining groups $(40-42 \%)$; this finding is the reverse of that of Stewart and others (1955). As already mentioned the firemen and ambulance drivers showed the lowest figure of all, there being only nine cases amongst 77 applicants $(12 \%)$.

Table 5 shows the numbers and percentages in each age group with visual defects, men and women together. There is a considerable increase in defects after the age of 50 . Sorsby and others (1955)

TABLE 5

AGE INCIDENCE OF VISUAL DEFECTS (MEN AND WOMEN)

\begin{tabular}{|c|c|c|c|}
\hline Age (yr.) & No. with Defects & Age (yr.) & No. with Defects \\
\hline $\begin{array}{c}\text { Under } 21 \\
21-25 \\
26-30 \\
31-35 \\
36-40\end{array}$ & $\begin{aligned} 9 & (18 \%) \\
77 & (33 \%) \\
69 & (31 \%) \\
69 & (39 \%) \\
39 & (40 \%)\end{aligned}$ & $\begin{array}{c}41-45 \\
46-50 \\
51-55 \\
\text { Over } 56\end{array}$ & $\begin{array}{ll}31 & (39 \%) \\
26 & (37 \% \\
34 & (66 \%) \\
22 & (70 \%)\end{array}$ \\
\hline \multicolumn{2}{|c|}{ Total (men and women) } & & 376 \\
\hline
\end{tabular}

(op. cit.) only investigated men up to the age of 40 years, but they found a steady increase in defects with age as also did Stewart and others (op. cit.).

Out of the 376 cases with defective vision, 282 $(75 \%)$ had both eyes defective and in $147(52 \%)$ of these the defect was equal in each eye; in $82(29 \%)$ the right eye was more affected than the left and in $53(19 \%)$ the left more than the right. In the $94(25 \%)$ who only had one eye defective, $53(56 \%)$ had the left eye affected and $41(44 \%)$ the right.

Colour Vision.-Colour vision was tested by means of Ishihara (1950) colour charts.* Defective colour vision was found in $39(6.5 \%)$ of the men and in five $(1.25 \%)$ of the women. No case of absolute colour blindness was seen. The male incidence was in agreement with previously published findings; for instance, Betenson (1955) gives a figure of $4 \%$ in schoolboys, Sorsby and others (1955) $5.8 \%$, and Duke-Elder (1938) quotes figures between $4 \%$ and $8 \%$ for males but only $0.4 \%$ for females.

Urine Tests.-The urine was tested for albumin by the boiling test, the result being recorded as "trace" meaning the merest suspicion of a cloud, " one plus" signifying a definite cloud which is not entirely opaque, "two plus" a definite opaque cloud, and "three plus" a dense, almost solid cloud. Each specimen was also tested for glycosuria using Benedict's reagent. The results of the urine tests were noted in only 760 cases $(459$ males and 301 females) as these were not recorded until after the survey had been under way for two months. Albumin

* Tests for Colour Blindness. H. K. Lewis, London. 9th ed. was present in only four specimens of the 459 males. Three of these men were under 35 years old and one of them was suffering from subacute nephritis. Two of the specimens from the 301 females showed albumin, in one case due to pyelitis and cystitis.

The figures given for the incidence of albuminuria in other groups vary considerably. Lyall (1941) found a figure of $0.55 \%$ among adult males examined for fitness for the Services, but quotes Diehl and McKinlay as giving an incidence of $5 \%$ in a group of university students. Recently Smiley (1955) found an incidence of $52 \%$ among a group of 87 accidentprone men and $7 \%$ in his controls. Some of this wide divergence may be due to differing definitions of "albuminuria"; it may be that some authors have ignored a " trace" and consider the test only positive at an ill-defined "one-plus" level. The cases in this series showed "one plus" in five cases and "three plus" in one case.

Glycosuria was found in five specimens from the men and in six from the women, one of whom was a known diabetic; in two known male diabetics the urine was sugar-free. Blotner (1946) found glycosuria in $2 \%$ of 69,088 male " selectees" aged 18 to 37 years. (The term " selectee" refers to those people examined for military service who have previously been examined by a local board; this board eliminates any person with gross disqualifying defects but the board did not screen out diabetics.) In Blotner's series $42 \%$ of those with glycosuria were considered to be diabetic. Previously he (Blotner and Hyde, 1943) had found an incidence of $0 \cdot 8 \%$ among 45,650 candidates. Spellberg and Leff (1945) found glycosuria in $1.1 \%$ of 32,003 selectees. The average incidence would therefore seem to be about $1 \%$ which is in agreement with the present findings.

\section{Modification of the Pulheems Profile for Record Purposes}

In the light of the experience of this survey the following procedure is now adopted. In addition to recording clinical information on the medical examination form (which is difficult to analyse), the following facts are separately recorded for each examination: name, sex, year of birth, proposed occupation, the height, weight, presence and approximate quantity of albumin and sugar in the urine, systolic and diastolic blood pressure readings, whether a registered disabled person, colour vision, and the P, U, L, H, E, E and S qualities adapted from the Pulheems system. The EE degrees are recorded as 1 to 8 as in the Pulheems system, but the other qualities (with the exception of $\mathrm{H}$ ) are only 
given a degree of 1,2 , or 3 . In the case of $P, U$ and $\mathrm{L}, 1$ is normal, 2 means a disability of minor or even no significance, and 3 signifies a disability of importance from the medical point of view. This method of making a medical rather than purely functional assessment renders the findings more readily comparable between different occupations and between different medical examiners. The $S$ quality is classified as S1 if there is no significant history of mental trouble, $\mathbf{S} 2$ if the applicant is now stable but gives a history of significant mental trouble, and S3 if the applicant is considered unstable at the time of the examination or if there is a history of mental breakdown within the previous two years. The quality $H$ is like $E E$ assessed functionally; $\mathrm{H} 1$ means that the applicant can hear a forced whisper at 10 feet, $\mathrm{H} 2$ that he hears the conversational voice at 10 feet, and $\mathrm{H} 3$ signifies deafness. Finally the actual defect is recorded. This system provides a simple and efficient method of collecting statistics of pre-employment medical examinations. As has already been shown such a system is of little or no value in selection and placement.

\section{Summary}

The Pulheems system of classification has been applied to 1,000 prospective employees. It was found that it provided too fine a screen for minor defects and too coarse a one for major defects. It was concluded that the Pulheems system could not usefully be applied to civilian employees and that it would be extremely difficult to modify the system so that it might be of use in widely differing industries and occupations. However, the system was found to be of value in collecting statistical information about the incidence of defects discovered at pre-employment medical examinations. Certain defects are discussed in detail including foot defects, pulmonary tuberculosis, psychoneurosis, hypertension peptic ulcers, defects of form and colour vision, and the incidence of albuminuria and glycosuria. A description is given of a modification of the Pulheems system for the purpose of statistical analysis of the results of routine medical examinations.

I wish to thank Dr. C. W. J. Ingham and Dr. V. Wiley for advice concerning the examinations and standards of fitness, and Dr. J. A. Scott, O.B.E., Medical Officer of Health, London County Council, for permission to publish this paper. The views expressed are those of the author and do not necessarily represent the views of the London County Council.

\section{REFERENCES}

Betenson, W. F. W. (1955). Med. Offr, 94, 169

Blotner, H. (1946). J. Amer. med. Ass., 131, 1109

Blotner, H. (1946). J. Amer. Med. Ass., 131, 1109.

Crew, F. A. E. (1953). History of the Second World War. The Army
, Hed Medical Services, Vol. 1. H.M.S.O., London.

Doll, R., and Jones, F. Avery (1951). Spec. Rep. Scr. med. Res. Coun. (Lond.), No. 276.

Duke-Elder, W. Stewart (1938). Text-book of Ophthalmology. Vol. 1. Kimpton, London.

Fishberg, A. M. (1954). Hypertension and Nephritis, 5th ed. Lea and Febiger, Philadelphia.

Fletcher, R. T. (1949). Brit. med. J., 1, 83

Forssman, S. (1955). Bull. Wld Hlth Org. 13, 495.

Hanman, B. (1951). Physical Capacities and Job Placement. Stock-

holm. 745 .

Lee, J. A. H. (1955). Proc, roy. Soc. Med., 48, 653.

Lewis, M. M. (1952). Ibid., 45, 472.

Lyall, A. (1941). Brit. med. J., $2,113$.

Newquist, M. N. (1955). In Trans. Conference Industrial Hygiene Foundation of America, 1954. Pittsburgh.

Pickering, G. W. (1955). High Blood Pressure. Churchill, London. Smiley, J. A. (1955). British Journal of Industrial Medicine, 12, 263. Sorsby, A., Benjamin, B., and Yudkin, J. (1955). Brit. J. prev. soc. Med., 9, 1.

Spellberg, M. A., and Leff, W. A. (1945), J. Amer, med. Ass. 129, 246 Spellberg, M. A., and Leff, W. A. (1945). J. Amer. med. Ass., 129, 246. Churchill, London.

Stewart, A. M., Webb, J. W., and Hewitt, D. (1955). Brit. J. prev. soc. Med., 9, 19. 